\title{
Phylogeography of Populus alba (L.) and Populus tremula (L.) in Central Europe: secondary contact and hybridisation during recolonisation from disconnected refugia
}

\author{
Barbara Fussi • Christian Lexer • Berthold Heinze
}

\begin{abstract}
The central aim of this paper is to clarify the picture of postglacial recolonisation and the reconstruction of refugia of Populus alba (L.) and Populus tremula (L.) in the light of hybridisation of the two species. We focussed our study on Central and Southeastern Europe including reference samples from Spain, Sweden and Northern Africa.We investigated 414 individuals of 26 populations using restriction fragment length polymorphisms (PCR-RFLPs) in six maternally inherited chloroplast markers. Altogether, 57 haplotypes were analysed of which four indicated hybridisation events in the past. Phylogeographic structure was found for $P$. alba with low diversity in Eastern Europe versus high diversity in Italy and Central Europe. A lack of phylogeographic structure was assessed for $P$. tremula as expected for a boreal forest tree, and diversity was evenly distributed in the studied populations. Two main refugia were identified for $P$. alba in Italy and Romania. A previously described hybrid zone between species in Central Europe turned out also to be a zone of contact between southern and eastern chloroplast lineages in $P$. alba. In contrast, $P$. tremula recolonised its
\end{abstract}

B. Fussi $(\bowtie) \cdot$ B. Heinze

Department of Genetics,

Federal Research and Training Centre for Forests,

Natural Hazards and Landscape,

Hauptstrasse 7,

1140 Vienna, Austria

e-mail: Barbara.Fussi@asp.bayern.de

\section{Lexer}

Unit of Ecology and Evolution, Department of Biology,

University of Fribourg,

1700 Fribourg, Switzerland present habitats in Central Europe from several refugia near the former ice cap. We assume separate disconnected refugia for $P$. alba and $P$. tremula and suggest an immigration scenario involving the mixing of colonisation routes and interspecific introgression to be responsible for the observed patterns.

Keywords Postglacial recolonisation $\cdot$ Hybridisation PCR-RFLPs $\cdot$ cpDNA $\cdot$ Populus alba $\cdot$ Populus tremula

\section{Introduction}

Phylogeographic patterns in Europe are highly influenced by the ice ages, especially affecting Northern Europe and the mountain chains (Taberlet et al. 1998). Forests were much more restricted than today, because of the climatic conditions and after the retreat of the ice shields, migration shaped today's species distribution ranges (Petit et al. 2003). Although detailed postglacial migration routes differ between species, they can be illustrated by ten model plant and animal species (Taberlet et al. 1998). Thermophilous taxa fit into these models (e.g., Quercus spp., Dumolin-Lapegue et al. 1997; Populus nigra, Cottrell et al. 2005), while boreal taxa apparently survived further north (Acer sp. and Populus tremula, Bittkau 2002; Betula sp., Maliouchenko et al. 2007). Boreal populations of the genus Salix and P. tremula (Petit et al. 2003) do not show high differentiation, in line with the assumption of additional northern refugia close to the ice shields. Fossil pollen records and charcoal remains provide evidence for the survival of trees on favourable sites along the southern edge of the permafrost during the last glacial maximum (LGM; Taberlet et al. 1998).

Although poplars have dispersal distances of up to $16 \mathrm{~km}$ (Slavov et al. 2004), seedling establishment relies 
on connexions between patches of suitable habitat types. This is particularly true for tree species bound to river ecosystems. The Danube in Europe provides an uninterrupted drainage system and connects sites close to the former ice sheet of the LGM with warm and dry areas in the Southeast of Europe, providing a corridor in periods that are warmer or cooler than today. Depending also on their specific dispersal abilities, high mountains or large water bodies most often represent barriers for movements of plants and animals; i.e., affecting seed viability after travelling by wind or submersion in water or even salt water.

In contrast to other species with detailed pollen records (e.g., oak, Quercus spp., Dumolin-Lapegue et al. 1997), Populus pollen is less viable, and fossil pollen data are scarce. Lack of pollen data complicates the search for glacial refugia for members of the genus (Huntley and Birks 1983): there is, for example, some evidence for pollen in low concentrations (1-5\%) from 9,000 BC onwards, along the northwestern rims of the Alps, in close proximity to the then glaciated Alps themselves (Huntley and Birks 1983). Although terrestrial plants are sessile, they can overcome long distances via pollen and seed dispersal, sometimes exhibiting surprisingly high migration speeds (e.g., Quercus sp. up to $500 \mathrm{~m}^{\text {year }}{ }^{-1}$ and Alnus sp. up to 2,000 mear $^{-1}$ of range expansion after the LGM, Huntley and Birks 1983). Like in most angiosperms, chloroplasts are maternally inherited in Populus (Rajora and Dancik 1992), thus they facilitate the understanding of migration events in the past and can serve as a proxy for lacking pollen data.

During the entire Pleistocene, range expansions and contractions of different species took place and influenced present-day patterns of diversity in many taxa (Widmer and Lexer 2001). These past demographic processes often led to hybridisation and are now more and more acknowledged to play a major role in the evolution of the genus Populus (Hamzeh and Dayanandan 2004). During the course of speciation, geographic and/or reproductive isolation at the intra-specific level are the main driving forces and species formation is understood as a by-product of intra-specific evolution (Stearns and Hoekstra 2005). Hybridisation occurs in two scenarios in which reproductive isolation is not complete: In the first one, species are separated geographically but not reproductively, thus hybridisation occurs after secondary contact of the species. This concept explains most of the hybrid zones in the Alps and in the Pyrenees, where divergent lineages have come into contact during postglacial recolonisation, thereby forming hybrids or even new species (Hewitt 2001). A second scenario involves hybrid zones between divergent populations in the process of parapatric speciation, but distinguishing this scenario from secondary contact is not trivial (Coyne and
Orr 2004). Further research is required to estimate species interaction models and accurate timing of contact and divergence more reliably (Comes and Kadereit 1998; Coyne and Orr 2004) and natural hybrid zones provide the opportunity to study such evolutionary processes and concepts (Lexer et al. 2005, 2007).

Hybridisation is not easy to detect, neither morphologically nor genetically. The status of Populus hybrids has been discussed for decades and still new concepts emerge (Eckenwalder 1996; Dickmann and Kuzovkina 2008). The grey poplar (Populus x canescens, Aiton, Sm.) is a natural hybrid between white poplar (Populus alba, L.) and European aspen (P. tremula, L.). Morphological distinction between them is based mainly on leaves and flower catkin bracteoles, but the variability within each species is enormous, and intermediate forms exist (Fischer et al. 2005; Eckenwalder 1996). P. x canescens occurs where the habitats of both parental species come into contact (Fischer et al. 2005) to form hybrid zones. More frequently, grey poplar is found close to the floodplain forests of $P$ alba (Lazowski 1997). To our knowledge, hybrid fitness has never been estimated directly, but population genetic work indicates the presence of many recombinant individuals in hybrid populations so it appears that F1 fitness is not seriously impaired (Lexer et al. 2005). Also, P. x canescens exhibits slightly increased vegetative fitness compared to $P$. alba in the Danube floodplain forest as indicated by greater levels of asexual reproduction (van Loo et al. 2008).

Both parental species are pioneer trees. $P$. alba is a characteristic of floodplain forests, $P$. tremula, on the other hand, is a pioneer species of upland forests, with greater ecological amplitude/plasticity. Both species and their hybrids are usually diploid (van Dillewijn 1940).

Although the genus Populus has been studied intensively in the past and is now considered as a model forest tree (Tuskan et al. 2006), there is a lack of knowledge about historical range expansions of white poplar and European aspen (Lexer et al. 2005, 2007), which is why the objectives of this study are (a) to trace the postglacial migration routes of $P$. alba and $P$. tremula, (b) to discuss the possible survival of the species in a Danube refugium during the LGM, and (c) to explore the extent to which species interactions such as hybridisation and introgression may influence phylogeographic inference based on cpDNA markers in these species. The limited data currently available on patterns of cpDNA diversity in parapatric $P$. alba and $P$. tremula in Central Europe suggest that introgression of the chloroplast DNA molecule is rare (Lexer et al. 2005). Thus, our expectation at the outset was that a comparative phylogeographic analysis of the two species should be feasible, as long as the possibility of occasional introgression is taken into account in the analysis. 


\section{Materials and methods}

Plant material

Species identification was based on botanical criteria (Fischer et al. 2005). Hybrids were identified based on morphology as well, based on the expectation that leaf morphology can predict the genotype reasonably well as long as many independent traits are considered simultaneously (Lexer et al. 2009).

As leaf dimorphism (heterophylly) is a further issue in the genus Populus (Bartels 1987), species identification was performed considering the appearance of the entire tree, including long and short shoots. Fully developed leaves on both short and long shoots were assessed for the following three morphological traits: leaf shape, leaf margin, and pubescence, based on the current excursion flora of Austria (Fischer et al. 2005). Typical leaves for P. alba were three- to five-lobed and coarsely toothed. Leaves from the long shoots had downy-white undersides and those from short shoots were downy-grey. $P$. tremula leaves were round with a sinuate margin and short blunt teeth, and neither short nor long shoots had a downy surface. The hybrid $P . x$ canescens had triangular to ovoid leaf shapes with lobes or irregularly spaced, coarse dentation. The undersides of leaves from long shoots were downy-grey and those of leaves from short shoots were slightly downy-grey to glabrous. Those criteria were utilised to identify samples from our own collections and from those obtained by our collaborators (for details of sampling see Appendix S1).

Leaves and buds were obtained from altogether $n=414$ trees, grouped into 26 populations. Nineteen populations dominated by $P$. alba (281 individuals) and seven populations dominated by $P$. tremula (133 individuals) were studied. Leaf morphological traits were assessed to estimate the proportion of hybrids ( $P$. $x$ canescens) in each population. Distances between samples in a population were as large as possible in order to avoid sampling of closely related individuals or clones (especially $P . x$ canescens can form large clones, van Loo et al. 2008). Leaf material was dried in silica gel. Small branches with buds were stored at $-20^{\circ} \mathrm{C}$.

\section{Study sites}

The location of the sampled populations is given in Fig. 1 and the numbers correspond to sampling information given in Appendix S1. Natural populations in Central and Southeastern Europe were intensively sampled. Samples from Italy and Czech Republic were obtained from clone collections and provided by collaborators there. Those samples were grouped into populations according to original collection sites; those collections were established in order to cover high genetic diversity and thus, original collection sites had a wide geographic distribution. Reference populations with low numbers of individuals from Spain, Morocco, Tunisia and Sweden completed the picture. The Spanish and the Italian samples had been chosen on the basis of their variation in chloroplast microsatellite patterns (S. González-Martínez and S. Castiglione, personal communications).

\section{DNA extraction}

DNA was extracted from approximately $10 \mathrm{mg}$ of dry or $50 \mathrm{mg}$ of fresh material, using the DNeasy 96 plant kit (Qiagen) or the CTAB method (Doyle and Doyle 1987). Polymerase chain reaction (PCR) and PCR-RFLP conditions were as given in Lexer et al. (2005), using the six primer pairs and five enzymes listed in Table 1. Primer pairs were chosen among the 'universal' ones listed at: http://bfw.ac.at/ bfwcms.web?dok=4961 (Heinze 2007). Amplification and restriction products were visualised in 2.5\% agarose gels stained with ethidium bromide. Fragment scoring was done manually, except for the fragment II (rpl16R1516+ rpl16F71R), which showed a high variability (Table 1) with apparent 16 base-pair repeats. Therefore, for this fragment, one primer was marked with fluorescent dye (D2, D3 or D4, Sigma-Proligo, USA), and the restriction products were analysed on a Beckman CEQ 8000 automatic sequencer for exact length determination.

Data analysis - gene diversity and differentiation; phylogeography

Diversity values (gene diversity and haplotypic richness) and distance measures were calculated. Gene diversity (diversity of unordered alleles, $h_{\mathrm{T}}$ ) is frequency dependent and accounts for relative diversity in a population. Haplotypic richness is equal to allelic richness in the case of chloroplasts. Haplotypic richness (diversity of ordered alleles, $v_{\mathrm{T}}$ ) is dependent on the sample size (Table 2). Both measures, $h_{\mathrm{T}}$ and $v_{\mathrm{T}}$, were calculated using the programmes HAPLODIV (Pons and Petit 1995) and CONTRIB (Petit et al. 1998). Haplotypic diversity requires standardisation for the smallest sample size (rarefaction-five in our case), which is implemented in HAPLODIV.

Genetic distance was calculated between pairs of haplotypes (the number of different alleles between two RFLP haplotypes) using analysis of molecular variance (AMOVA), as implemented in the software ARLEQUIN (Schneider et al. 2000). Different hierarchical levels were tested and significance was calculated at the $p<0.001$ level after 10,000 permutations.

The relationship between populations was calculated in PHYLIP (Felsenstein 2004) based on Reynolds, Weir and Cockerham's genetic distance (1983). An unrooted UPGMA tree was constructed, and branch support was 


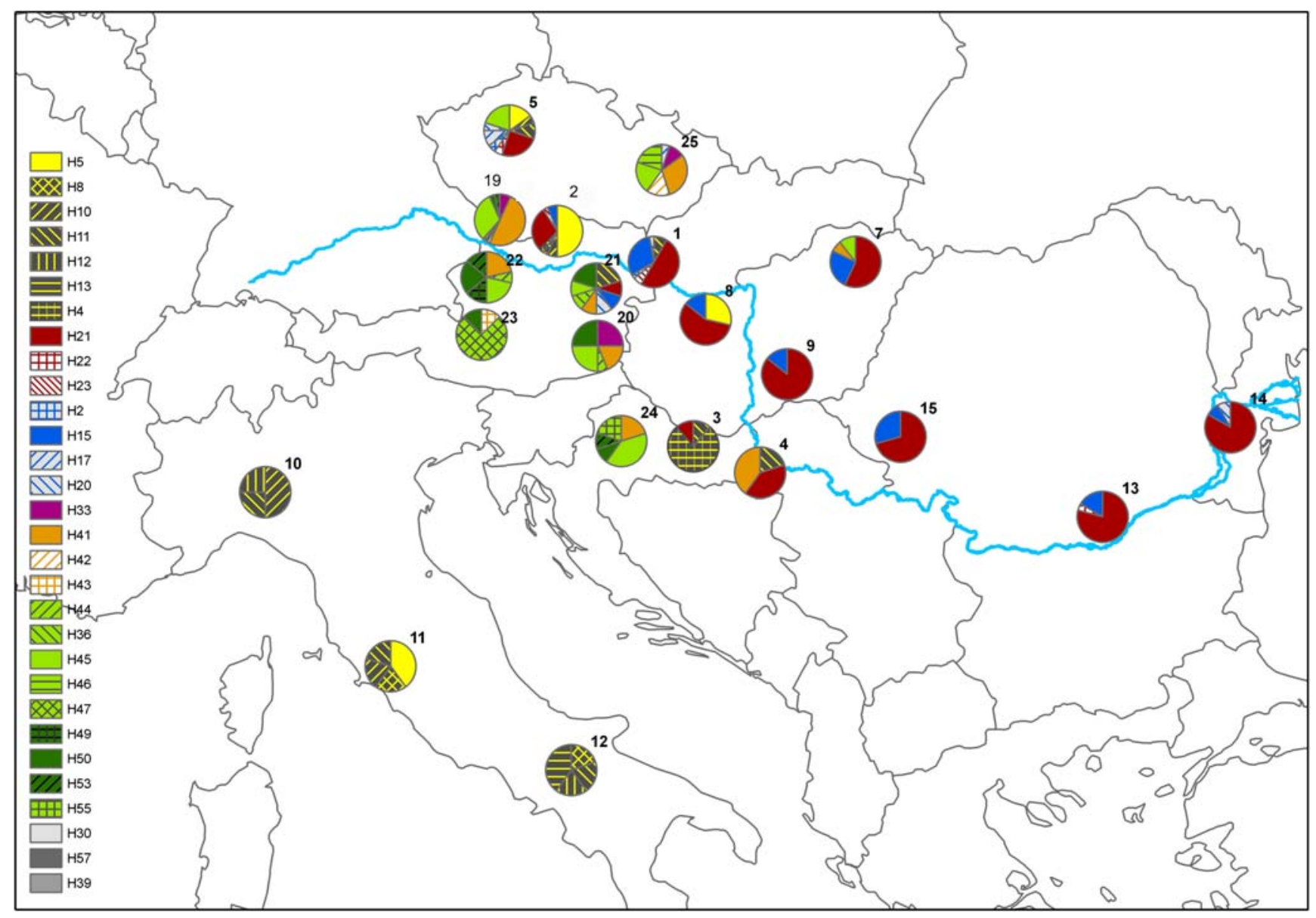

Fig. 1 Geographic distribution of chloroplast PCR-RFLP haplotypes for $P$. alba and $P$. tremula in Central, Southern and Southeastern haplotype network of $P$. alba (red, blue, yellow) and P. tremula (green, orange). Frequencies for populations from Sweden, Spain, Greece, Tunisia and Morocco are illustrated in the Appendix S3

assessed using 1,000 bootstraps in the SEQBOOT software of the PHYLIP package. Shorter distances are expected for geographically closer populations under a model of isolation-by-distance. Interspecific hybridisation can disrupt such within-species patterns because hybridisation tends to be a localised phenomenon. Thus, hybridisation can affect branching patterns detected in distance-based analysis.

The presence of phylogeographic structure was estimated by measures of differentiation - the proportion of diversity between populations to total variation, termed $G_{\mathrm{ST}}$ for

unordered and $N_{\mathrm{ST}}$ for ordered alleles, respectively. The relationship between both measures can reveal whether phylogeographic structure is present in a set of populations (Pons and Petit 1996); it was calculated for each species separately in HAPLODIV (Pons and Petit 1995) and PERMUT (Pons and Petit 1996). Phylogeographic structure is evident if $N_{\mathrm{ST}}>G_{\mathrm{ST}}$, i.e., if the proportion of more closely related haplotypes in one population is higher than the proportion of unrelated haplotypes. Significance was tested at the $p<0.05$ and $p<0.01$ levels after 10,000 permutaions.

Table 1 Patterns of variation obtained with different primer-restriction enzyme combinations in $P$. alba and $P$. tremula

\begin{tabular}{lllllll}
\hline Fragment number & Forward primer & Reverse primer & Observed length (bp) & Restriction enzymes & Variable fragments & Characters \\
\hline I & trnDP & trnTP & 1,066 & HinfI & 2 & a,b,c,d/a,b,c \\
II & rpl16R1516 & rpl16F71R & 1,180 & EcoRI+HhaI & 1 & a,b,c,d,e,f,g,h \\
III & rpl16ex1f & rps3r2 & 800 & EcoRI+HhaI & 1 & a,b,c \\
IV & rps3f2 & ccmp10R & 1,020 & HhaI+SspI & 1 & 1 \\
V & atpBSAM & rbclSAM & 850 & EcoRI & a,b,c,d \\
VI & ccmp10R & trnHM & 600 & MspI & 2 & a,b \\
\end{tabular}


Table 2 Diversity statistics of 414 individuals in 26 populations, sorted by decreasing haplotypic richness, given for $P$. alba and $P$. tremula separately

\begin{tabular}{|c|c|c|c|c|c|c|}
\hline Species & Population & No. of haplotypes ${ }^{a}$ & No. of polymorphic sites & Gene diversity ${ }^{\mathrm{b}}$ & Haplotypic richness ${ }^{\mathrm{c}}$ & $\mathrm{P}^{\mathrm{d}}$ \\
\hline P. alba & Viennese Forest_c & $8(10)$ & 7 & $0.955(0.059)$ & 4.556 & 0.6 \\
\hline P. alba & Central Italy & $5(6)$ & 3 & $0.933(0.121)$ & 4.333 & 0 \\
\hline P. alba & Southern Italy & $5(6)$ & 3 & $0.933(0.121)$ & 4.333 & 0 \\
\hline P. alba & Czech Republic_alba_c & $12(23)$ & 7 & $0.917(0.034)$ & 4.251 & 0.26 \\
\hline P. alba & Spain & $6(8)$ & 5 & $0.892(0.111)$ & 4.107 & 0 \\
\hline P. alba. & Tunisia & $4(6)$ & 6 & $0.866(0.129)$ & 3.667 & 0 \\
\hline P. alba & Vienna Danube_c & $11(41)$ & 5 & $0.741(0.053)$ & 3.181 & 0.44 \\
\hline P. alba & Western Hungary_c & $4(8)$ & 4 & $0.750(0.139)$ & 3.143 & 1 \\
\hline P. alba & Eastern Croatia_alba & $3(5)$ & 7 & $0.800(0.164)$ & 3.000 & 0 \\
\hline P. alba & Northern Austria_alba_c & $7(32)$ & 4 & $0.681(0.139)$ & 2.865 & 0.38 \\
\hline P. alba & Eastern Hungary_c & $4(28)$ & 6 & $0.616(0.077)$ & 2.575 & 0.89 \\
\hline P. alba & Central Romania & $6(27)$ & 4 & $0.495(0.109)$ & 2.323 & 0 \\
\hline P. alba & Central Croatia_c & $3(9)$ & 4 & $0.416(0.190)$ & 2.111 & 0.78 \\
\hline P. alba & Western Romania & $2(17)$ & 2 & $0.441(0.097)$ & 1.872 & 0 \\
\hline P. alba & Eastern Romania & $3(12)$ & 2 & $0.318(0.163)$ & 1.833 & 0 \\
\hline P. alba & Southern Hungary_c & $3(29)$ & 2 & $0.305(0.100)$ & 1.725 & 1 \\
\hline P. alba & Crete & $1(7)$ & 0 & 0.000 & 1.000 & 0 \\
\hline P. alba & Northern Italy & $3(4)$ & 1 & $0.833(0.222)$ & n.incl. & 0 \\
\hline P. alba & Morocco & $1(3)$ & 0 & 0.000 & n.incl. & 0 \\
\hline P. tremula & Northern Alps & $6(12)$ & 3 & $0.879(0.046)$ & 3.874 & 0 \\
\hline P. tremula & Czech Republic_trem & $8(22)$ & 6 & $0.865(0.040)$ & 3.835 & 0 \\
\hline P. tremula & Eastern Croatia_trem_c & $5(10)$ & 2 & $0.822(0.096)$ & 3.532 & 0.4 \\
\hline P. tremula & Eastern Alps & $5(16)$ & 3 & $0.825(0.044)$ & 3.474 & 0 \\
\hline P. tremula & Central Alps & $3(8)$ & 2 & $0.464(0.200)$ & 3.000 & 0 \\
\hline P. tremula & Northern Austria_trem_c & $10(62)$ & 7 & $0.675(0.044)$ & 2.827 & 0.27 \\
\hline P. tremula & Sweden & $2(3)$ & 3 & $0.666(0.314)$ & n.incl. & 0 \\
\hline
\end{tabular}

Average sample size per population for P. alba was 14.8 and for P. tremula, 19

$c$ presence of P. $x$ canescens based on botanical identification in the field, n.incl. populations not included in the calculation of haplotypic richness because of too small sample size

${ }^{\text {a }}$ Sample size in brackets

${ }^{\mathrm{b}}$ Standard deviation in brackets

${ }^{\mathrm{c}}$ Rarefaction to five individuals

${ }^{\mathrm{d}}$ Portion of morphological hybrids, 0 means no hybrids, 1 means $100 \%$ hybrids

Relationships among haplotypes were assessed on the basis of a median-joining network, using the software NETWORK (http://fluxus-engeneering.com, Bandelt et al. 1999). The programme searches for a minimum spanning tree with the shortest possible connexions with the help of median vectors, which act as starting points for connexions between haplotypes. In this analysis, the data set was reduced from 57 to 30 haplotypes by excluding singletons for clarity. Haplotype frequency maps were established in order to allow geographic and historic interpretation essentially following Posada and Crandall (2001).

The haplotype networks were also employed in assessing the impact of hybridisation on phylogeographic inference, as haplotypes are characteristic and clearly separated according to species (Lexer et al. 2005). Haplotypes of apparent morphological hybrids were scrutinised for their position in the network, and congruence between our species designations and the haplotype positions in the network was assessed.

\section{Results}

Altogether, ten populations were affected by hybridisation, whereas 16 populations did not show any sign of hybrids based on the morphological identification criteria. Proportions of morphological hybrids in each population varied considerably from $27 \%$ to $100 \%$. Hybridisation appeared to 
be more frequent in $P$. alba with eight out of 16 populations harbouring morphological hybrids (Table 2). For P. tremula, two out of seven populations contained morphological hybrids. No morphological signs of hybridisation were detected where both species occurred isolated from each other; i.e., Romania and Crete for P. alba, Central and Northern Alps and Sweden for P. tremula.

\section{Molecular variation}

Six PCR-RFLP fragments yielded 35 length polymorphisms, combining into 57 haplotypes in the 26 populations (414 individuals). Haplotype descriptions are given in Appendix S2. Total diversity for $P$. alba was $h_{\mathrm{T}}=0.898$ and $v_{T}=0.907$ for unordered and ordered alleles, respectively. The values for $P$. tremula were slightly higher, $h_{\mathrm{T}}=0.905$ and $v_{\mathrm{T}}=0.915$. Diversity values for populations are listed in Table 2, sorted by decreasing haplotypic richness. The highest haplotypic richness was found in population Viennese Forest_c (4.5 haplotypes after rarefaction) followed by the Mediterranean populations. Central European populations yielded higher haplotypic richness compared to Southeastern European ones. Calculation of molecular variance (AMOVA) revealed great and significant differentiation among species of $54.5 \%$, consistent with earlier reports of very low levels of chloroplast DNA introgression (Lexer et al. 2005). Differentiation between populations was higher in $P$. alba (36.3\%) than in P. tremula (18.6\%). Within populations, $P$. tremula had higher diversity (81.4\%) than P. alba (63.7\%).

Geography and genetic relationships

The UPGMA tree revealed separation of most populations of $P$. tremula from those of $P$. alba with moderate bootstrap support. Populations of $P$. alba were further split into several groups (Fig. 2), the groupings within the Danube drainage system receiving $65-100 \%$ bootstrap support. Two of the $P$. alba groups had evidence for the presence of hybrids based on our morphological identification. The Danube drainage system clade had the highest proportion of intermediate morphotypes $(51.4 \%)$ followed by the Central European group of $P$. alba with $24.5 \%$ of intermediate morphotypes. The Italian group of $P$. alba was well defined by private haplotypes, and populations from Northern and Central/ Southern Italy were clearly separated (Fig. 2). No morphological evidence for hybridisation was found in Italian populations. The remaining samples of $P$. alba from the Mediterranean basin (Crete, Tunisia and Morocco) grouped together with the clade containing mainly populations of $P$. tremula with low bootstrap support. A conspicuous result was the positioning in close proximity of the Swedish and Spanish samples within the $P$. tremula group, as the Spanish samples comprised $P$. alba morphotypes.
Phylogeographic patterns

Comparing $N_{\mathrm{ST}}$ and $G_{\mathrm{ST}}$ revealed a highly significant phylogeographic structure for $P$. alba (Table 3), where related haplotypes were more frequently found within the same population. The Italian populations were dominated by three haplotypes (Figs. 1 and 3, yellow) exclusively distributed in Italy, whereas two additional Italian haplotypes were also present in Croatia, Hungary, Austria and the Czech Republic. P. alba populations along the Danube were dominated by two exclusive haplotypes (H21, H15). Populations from smaller rivers in the Danube basin were characterised by additional haplotypes (H4 in Central Croatia and Northern Austria, Fig. 1). In populations from Northern Austria and the Czech Republic, one Italian haplotype H5 (yellow) occurred frequently, indicating admixture from this refugial area. In contrast, no significant difference between $N_{\mathrm{ST}}$ and $G_{\mathrm{ST}}$ was detected in P. tremula (Table 3), indicating a weak phylogeographic structure in this species. Two haplotypes (H41, H45) dominated P. tremula in the majority of the populations. North African populations of $P$. alba were grouped with the $P$. tremula clade and were characterised by two haplotypes (H39, H57) separated from other haplotypes by six mutational steps. The sample from Crete was fixed for a single haplotype (H30).

Network supports relationship of haplotypes

Grouping of the haplotypes (omitting singletons) within a mutational framework resolved them into network-type clusters (Fig. 3). Haplotypes from H1 to H30 were typical for $P$. alba, whereas haplotypes $\mathrm{H} 31$ to $\mathrm{H} 57$ were typical for P. tremula. The haplotypes in the network are clearly split into two clades. Haplotypes in the upper clade predominantly appeared in populations of $P$. tremula. The haplotypes in the lower clade were mainly found in populations of $P$. alba. Only few haplotypes occurred in both species (indicated by arrows in Fig. 3). Haplotype H33, connecting both clades, was distributed in three populations of $P$. tremula in Central Europe and in Sweden and additionally appeared in the Spanish P. alba population.

\section{Discussion}

The two poplar species in this study ( $P$. alba and $P$. tremula) hybridise in nature, thus hampering field identification, if only single traits are considered. Morphological species identification based on many traits revealed a substantial proportion $(22.2 \%)$ of potential hybrids in the studied populations (Table 2). Of course this can only be a very coarse assessment of hybridisation because only a limited number of genes are involved in characterising leaf 


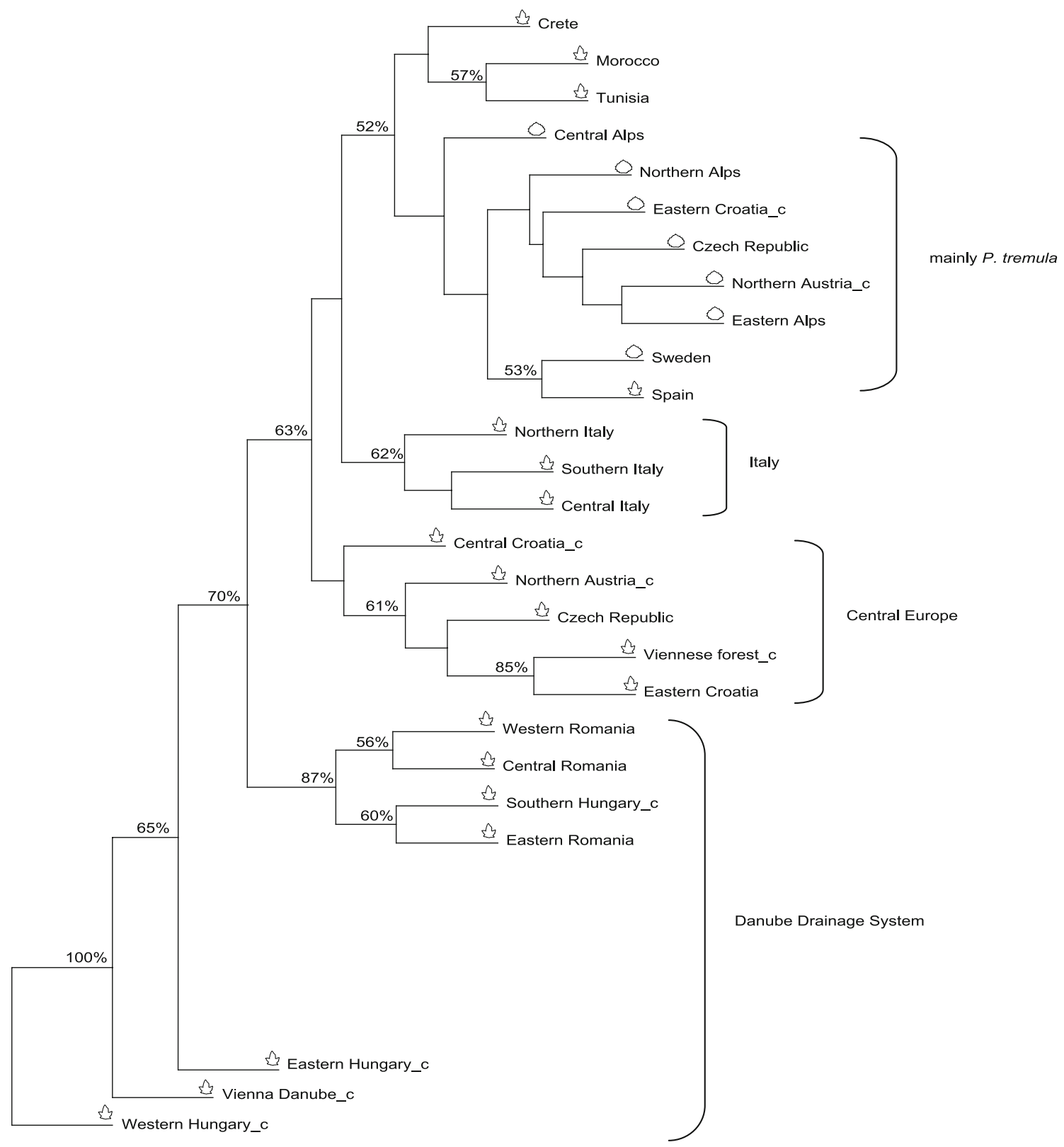

100

Fig. 2 Relationships among 26 populations visualised in an unrooted UPGMA tree based on pairwise population distance values, revealing four main groups dominated by species and geographical relationship of $P$. alba, P. x canescens and P. tremula supported by bootstrap analyses based on 1,000 replications (only values higher than $50 \%$ are

morphology. A more profound assessment of hybridisation was undertaken in previous studies of our groups in a subset of populations of this study based on microsatellites. Those revealed hybridisation in three populations (Lexer et al. 2005, 2007; van Loo et al. 2008), suggesting that both shown). Species origin of the sampled populations is indicated by leaf symbols: lobed for $P$. alba and round for P. tremula. $c$ indicates the presence of $P . x$ canescens in the respective populations based on morphological identification

directions of hybridisation are possible in this species complex.

Hybridisation is complicating our attempts to reconstruct refugia and migration routes for the two species. Furthermore, it is difficult to locate refugia based on poplar and 
Table 3 Chloroplast diversity statistics and genetic differentiation for ordered and unordered alleles following Pons and Petit (1996) for P. alba and $P$. tremula, including population size and the number of haplotypes considered

\begin{tabular}{lllllllll}
\hline Species & Number of populations & Number of haplotypes & $h_{\mathrm{S}}^{\mathrm{a}}$ & $h_{\mathrm{T}}^{\mathrm{a}}$ & ${G_{\mathrm{ST}}}^{\mathrm{a}}$ & $v_{\mathrm{S}}^{\mathrm{b}}$ & $v_{\mathrm{T}}^{\mathrm{b}}$ & $N_{\mathrm{ST}}{ }^{\mathrm{b}}$ \\
\hline P. alba & 19 & 57 & 0.626 & 0.898 & 0.303 & 0.461 & 0.907 & 0.492 \\
P. tremula & 7 & 57 & 0.772 & 0.905 & 0.147 & 0.724 & 0.915 & 0.208
\end{tabular}

The difference in genetic divergence when estimated using unordered vs. ordered haplotype information $\left(G_{\mathrm{ST}} \mathrm{vs.} N_{\mathrm{ST}}\right)$ was highly significant $(p<$ $0.01)$ in P. alba, but not significant in P. tremula

${ }^{\text {a } U n o r d e r e d ~ h a p l o t y p e s: ~} h_{\mathrm{S}}$, within-population diversity; $h_{\mathrm{T}}$, total diversity; $G_{\mathrm{ST}}$, genetic divergence

${ }^{\mathrm{b}}$ Ordered haplotypes: $v_{\mathrm{S}}$, within-population diversity; $v_{\mathrm{T}}$, total diversity; $N_{\mathrm{ST}}$, genetic divergence

aspen pollen because pollen data are scarce in the fossil record (Huntley and Birks 1983). Moreover, species distinction of pollen is nearly impossible in European Populus species (R. Litschauer, BFW Vienna, personal communication). Therefore criteria for possible glacial refugia can currently only be derived from genetic data. The following criteria based on haplotype networks and diversity values can be applied (Posada and Crandall 2001): high-frequency and central haplotypes can be considered ancient, and populations carrying these haplotypes should be taken into consideration as representing possible refugia (or direct descendants of refugial populations). These 'rules' have been used extensively in the literature and rely on the assumptions underlying the coalescent process, hence they are associated with uncertainty. Haplotype diversity is another clue; it should be higher in possible refugia, unless it can be attributed to meeting points of zones of different postglacial routes (Petit et al. 2003).

In our study, we found strong phylogeographic structure within $P$. alba, supported by the $G$ st $/ N$ st test, but only weak structure within $P$. tremula. We conclude that $P$. alba populations have different phylogeographic histories be-

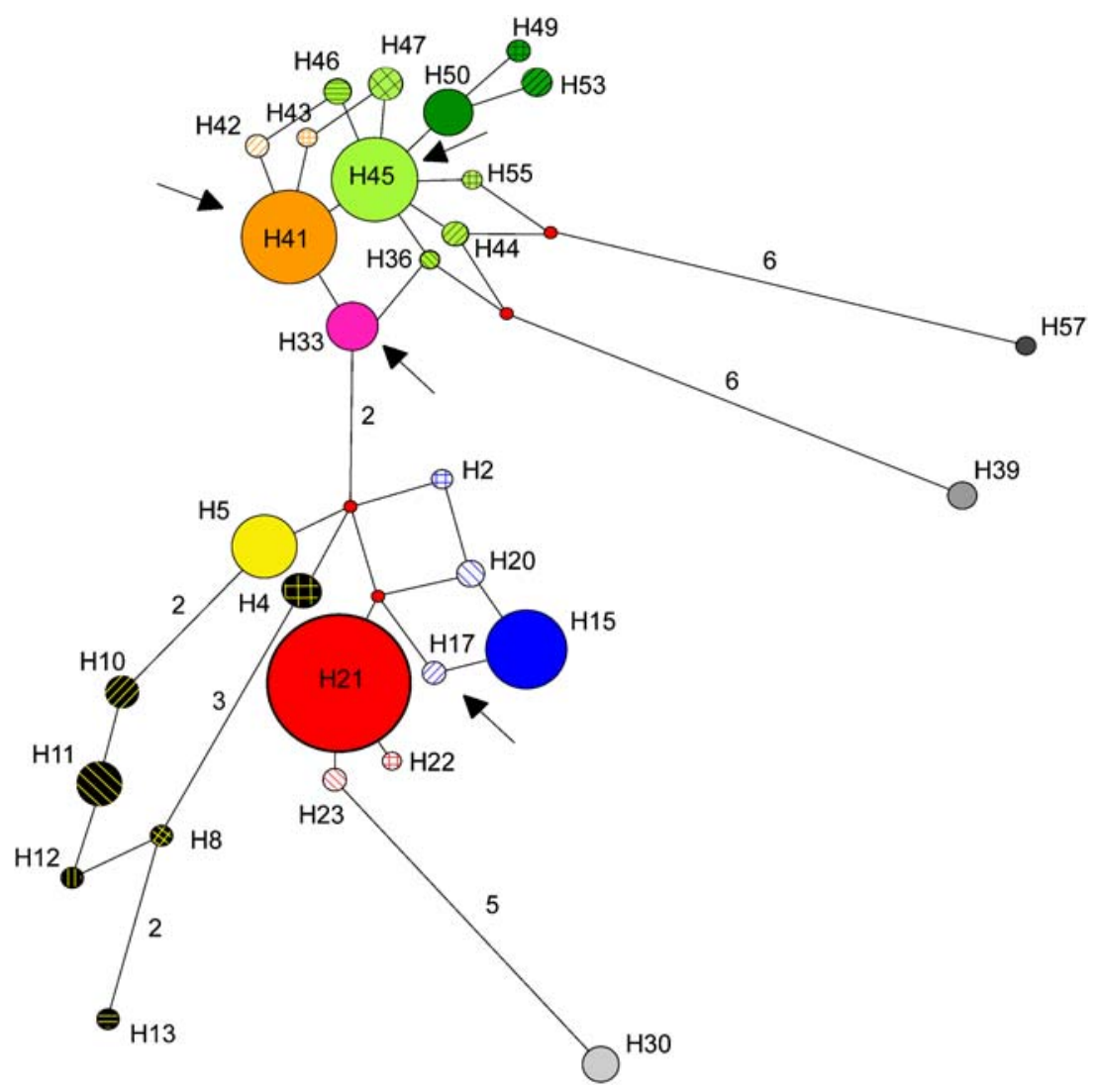

Fig. 3 Median-joining network of 30 haplotypes, without singletons. Colours and patterns correspond to Fig. 2 with P. alba in red, blue and yellow and $P$. tremula in green and orange. Size of circles correspond to number of individuals in a given haplotype and number of mutation steps between haplotypes is one except for those indicated along the connexions. Haplotypes found in hybrid morphotypes are indicated by arrows 
cause they survived the Quaternary glaciations in disconnected refugial areas. This is visible from the separate lineages characterising the Italian Peninsula and the Danube catchment (Figs. 1 and 3). Furthermore, the phylogenetic tree separated Central European and Southeastern populations of $P$. alba from Mediterranean and Italian populations with $63 \%$ bootstrap support (Fig. 2).

Because of the thermophilous nature of $P$. alba, its survival during the LGM must have been further south and/ or southeast compared to its present distribution, as shown for other thermophilous species such as oaks (Quercus sp., Dumolin-Lapegue et al. 1997). Northern habitats of $P$. alba were recolonised primarily via the Danube corridor as shown in Fig. 1 where Austrian haplotypes are related to those from further downstream along the Danube. For the Central European distribution range of $P$. alba, this is plausible because ecologically the species is dependent on large rivers like the Danube. A similar phylogeographic pattern has recently been shown for barbel fish (Barbus barbus, Kotlik and Berrebi 2001), a species in the Danube drainage system dominated by one major mitochondrial haplotype that originated in the Black Sea. A conspicuous result is that haplotypes from Italy were detected in Northern Austria and Czech Republic, but no Central European haplotypes were found in Italy. This pattern indicates that Italian populations contributed to the colonisation of Central Europe as well.

As a result of various recolonisation routes towards the north, mixing of haplotype lineages was detected in Austrian, Czech, Hungarian and Croatian populations of P. alba. In those populations, the proportion of admixed Italian haplotypes was $25-50 \%$. The remaining portion was made up by Eastern European or local private haplotypes. Mixing of lineages was likely to happen in those populations because habitats were newly established there during the melting process of the Alpine glaciers. For establishing new populations in that critical phase, two processes have to be considered. First, as the whole genus Populus has wind-dispersed seeds and pollen, long distance movements during recolonisation must be expected (Nathan 2006). In some cases, rare long distance dispersal events play a key role in structuring maternally inherited genes (Le Corre et al. 1997). Moreover, a suture zone was previously proposed for another 'fluviphilous' tree species, Fraxinus excelsior, in the North of the Pannonian basin (Hungary and Slovakia; Heuertz et al. 2004), on the basis of nuclear microsatellite data. Especially, the Eastern Alps were considered as a glacial refugium for several plant taxa (Niklfeld 1972, 1974). Secondly, newly arisen mutations might have taken advantage of a founder effect and changing river dynamics (see also P. nigra; Cottrell et al. 2005), which may explain high levels of cpDNA diversity in Austria. For instance, five haplotypes exclusive to the Vienna Danube_c popula- tion were present at low frequency. However, we do not expect a refugium in that area for $P$. alba due to its thermophilous nature. High diversity supported Italy as a refugial area for $P$. alba, with the presence of three exclusive haplotypes. On the contrary, diversity was surprisingly low in Romanian populations but the occurring haplotypes were central in the network and highly frequent in the populations, thus suggesting a possible refugium in Southeastern Europe as well. In this case, historic events and/or human impact may have caused the loss of genetic diversity (bottleneck) in Romanian populations.

We detected no phylogeographic structure for $P$. tremula in Central Europe, which supports the hypothesis that there were several connected refugia during the Quaternary glaciation cycles. This appears to have led to the relatively even haplotype distribution observed among the populations in our study. P. tremula as a boreal species followed the pattern of other boreal species with a more northern distribution and refugia and without clear phylogeographic patterns, i.e. Betula pendula (Maliouchenko et al. 2007) and Salix caprea (Palme et al. 2003).

A refugium for $P$. tremula can be assumed close to the ice shields of the LGM. We conclude that recolonisation from those refugia happened fast and thus, mixing of lineages from several refugia led to the current picture of high haplotypic diversity in the studied forests. Survival close to the ice shield is supported by the current distribution of $P$. tremula trees from 200 to $2,000 \mathrm{~m}$ above sea level. The ability of the species to cope with a great variety of ecological conditions and especially its tolerance towards cold temperature supports our conclusions. This is also supported by the rare but available pollen data from the early Holocene from Central and Northern Europe (Huntley and Birks 1983) together with macrofossil data of Populus wood dating back to $25,000 \mathrm{BC}$ on protected sites in Slovenia (Willis et al. 2000). Further arguments for the potential survival of trees near the ice shield can be derived from Davis et al. (2003), who found evidence for substantial local and seasonal climatic differences within a balanced regional and annual climate. Altogether, this feeds the ongoing debate about possible northern tree refugia (e.g., Willis et al. 2000; Willis and van Andel 2004; Carcaillet and Vernet 2001; Stewart and Lister 2001).

One of the most striking factors besides seed dispersal and mutations in shaping the phylogeographic pattern of the $P$. alba-P. tremula species complex was hybridisation. The alternations of cooling and warming during the Pleistocene provoked seesaw movements of the tree species according to their ecological requirements either as one of the first colonisers ( $P$. tremula) or trailing the recolonisation front line in some spatial and temporal distance $(P$. alba). Therefore, we believe that hybrids already have formed during earlier recolonisation processes. The formation and 
'good' separation of the species over a long evolutionary time period is supported by the clear separation of the two clades in the haplotype network. However, single haplotypes were able to jump across this divide, appearing in morphological hybrids or the other species (indicated with arrows in Fig. 3).

Perhaps the most striking case of haplotype sharing observed in the present study is that between Spanish $P$. $a l b a$ and Swedish P. tremula. We can only offer chloroplast capture or ancient haplotype sharing as possible explanations (see discussion in Rieseberg and Soltis 1991). P. $a l b a$, in a possible western refugium, may have captured chloroplasts from more widespread $P$. tremula there, but further sampling is required to support this result. Also, our UPGMA tree is unrooted, thus we cannot infer the direction of chloroplast capture from it. Nevertheless, the haplotype network (Fig. 3) provides indications for the identity of ancestral and derived haplotypes in each species. We also have to consider human transfer of material, but for the studied species, this seems very unlikely as they have not been of major commercial interest.

A second unusual case of haplotype sharing is the placement of the North African P. alba haplotypes into the $P$. tremula clade. Morphologically, these two populations represented two subspecies of $P$. alba, according to herbarium specimens from the Natural History Museum in London (UK): P. alba ssp. hickeliana (BM000794106) and P. alba ssp. subintegerrima (BM000794108). Genetically the two taxa were characterised by two distinct haplotypes, separated by six mutational steps (Fig. 3 and Appendix S3), and both were placed within the $P$. tremula clade. Again, recurrent interspecific gene flow and shared ancestral polymorphism are possible explanations. We suspect that these species share haplotypes more frequently than generally assumed - at least in the extreme western and eastern refugia; a situation already encountered in hybridising oak (Dumolin-Lapegue et al. 1997), birch (Palme et al. 2004) and ash species (Heuertz et al. 2006). Analysis of more samples from the Eastern Mediterranean (e.g., Turkey) would be necessary to complete the picture.

Looking further into the past of Central Europe reveals that towards the end of the Pliocene, climate was warmer and drier than today with poplars distributed along the coast of the Pannonian sea (Starmühlner and Aschenbrenner 1972). Tests of past population demography of $P$. tremula based on 77 genes revealed a severe bottleneck at the beginning of the Pleistocene (Ingvarsson 2008), thus suggesting that $P$. tremula was more widespread in the Pliocene. During the first cooling in the Pleistocene, thermophilous species were pushed further south and only cold tolerant lineages survived in Central Europe. Such historical processes may have played a role in shaping today's distribution ranges and hybrid zones in this area. As an example, we propose an immigration scenario for Central Europe on the basis of our findings (Fig. 4). We assume that $P$. tremula survived the last glaciation near the ice shield, close to the permafrost line. Thus, with progressive climate warming, this species was able to establish itself quickly in the area. Later, $P$. alba arrived mainly from Southeastern Europe and replaced $P$. tremula on the most favourable sites (e.g., population Vienna Danube_c), but in the more temperate hills (Viennese Forest_c), hybridisation and introgression occurred.

For explaining these patterns, we need to know more about the time of species divergence between $P$. tremula and $P$. alba. The exact timing of divergence is unknown and the two species may have repeatedly hybridised in previous interglacial periods. Our study points out that many more interesting insights may be gained from expanding our outlook further into the past (Hewitt 2004), thereby revealing species evolutionary histories with repeated interconnections that may have left their marks in today's genomes.
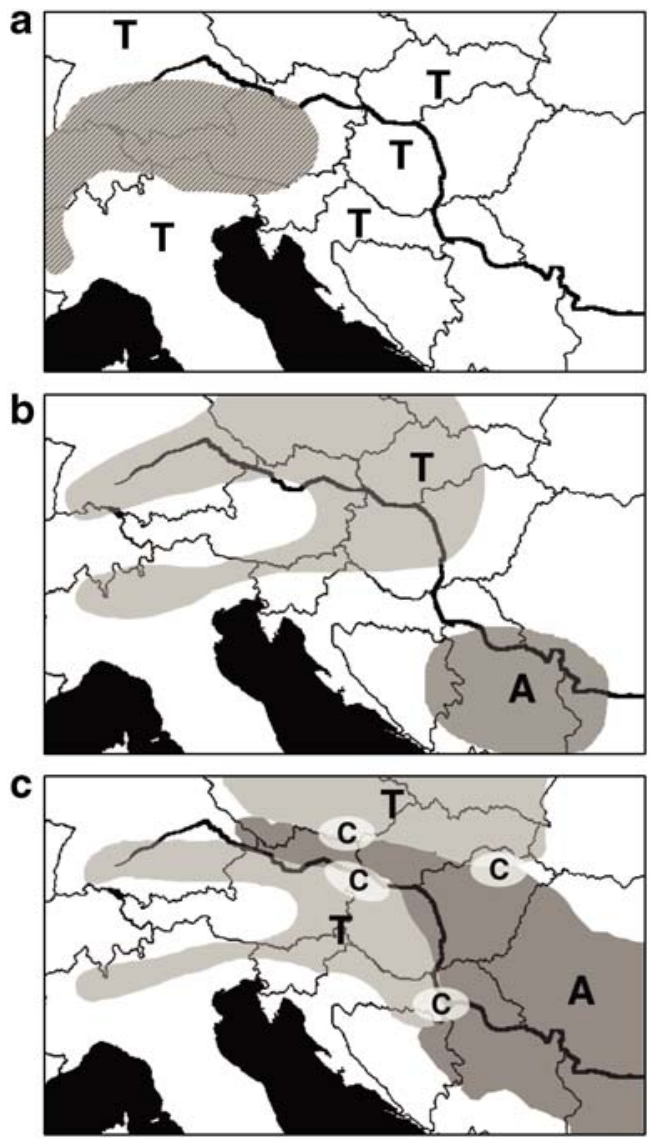

Fig. 4 Immigration scenario for $P$. alba and $P$. tremula in Central Europe after the last glacial maximum. a Possible refugia for $P$. tremula $(T)$ in close proximity to the ice shield (hatched area). b Range expansion of $P$. tremula $(T)$ while $P$. alba $(A)$ was still situated in its refugia. c Immigration of $P$. alba $(A)$ upstream the Danube: replacement of and hybridisation with P. tremula $(T)$ and forming $P . x$ canescens $(C)$ 
Acknowledgement We thank Wilfried Nebenführ, Hans Herz, Christian Fraissl, Franz Kovacs, Denes Bartha, Marius Sorin Nica and Adrian Ipati, for their help with sampling. We also thank Davorin Kajba, Sasa Bogdan, Attila Benke, Stefano Castiglione, Santiago GonzálezMartínez, Helena Cvrčková and Pavlina Máchová for providing us with samples. We thank Maria del Carmen Calderón Pérez for her great help in the laboratory. Helpful advice on statistical analysis was given by Remy Petit. We thank Karl-Manfred Schweinzer for helping in designing the haplotype maps. This study was financially supported by the city of Vienna (Jubiläumsfonds der Stadt Wien für die Österreichische Akademie der Wissenschaften, J-6/2005), a DOC-fFORTE grant to B. Fussi (Österreichische Akademie der Wissenschaften) and by grant NE/ E016731/1 of the British NERC to CL.

\section{References}

Bandelt H, Forster P, Rohl A (1999) Median-joining networks for inferring intraspecific phylogenies. Mol Biol Evol 16:37-48

Bartels H (1987) Die Gattung Populus aus dendrologischer Sicht. Die Holzzucht (Hann Münden) 41:1-7

Bittkau C (2002) Charakterisierung der genetischen Variation europäischer Populationen von Acer spp. und Populus tremula auf der Basis der Chloroplasten-DNA: Rückschlüsse auf die postglaziale Ausbreitung und Differenzierung forstlicher Provenienzen. Dissertation at the Technical University of Munich (Germany)

Carcaillet C, Vernet JL (2001) Comments on "The full-glacial forests of central and South Eastern Europe" by Willis et al. Quaternary Res 55:385-387

Comes HP, Kadereit JW (1998) The effect of quaternary climatic changes on plant distribution and evolution. Trends Plant Sci 3:432-438

Cottrell JE, Krystufek V, Tabbener HE, Milner AD, Connolly T, Sing L, Fluch S, Burg K, Lefevre F, Achard P (2005) Postglacial migration of Populus nigra L.: lessons learnt from chloroplast DNA. Forest Ecol Manag 206:71-90

Coyne JA, Orr HA (2004) Speciation. Sinauer Associates, Sunderland

Davis BAS, Brewer S, Stevenson AC, Guiot J, Data Contributors (2003) The temperature of Europe during the Holocene reconstructed from pollen data. Quaternary Sci Rev 22:1701-1716

Dickmann DI, Kuzovkina J (2008) Poplars and willows in the world. Chapter 2 Working Paper IPC/9-2. FAO, Rome

Doyle JJ, Doyle JL (1987) A rapid DNA isolation procedure for small quantities of fresh leaf tissue. Phytochem Bulletin 19:11-15

Dumolin-Lapegue S, Demesure B, Fineschi S, Lecorre V, Petit RJ (1997) Phylogeographic structure of white oaks throughout the European continent. Genetics 146:1475-1487

Eckenwalder JE (1996) Systematics and evolution of Populus. In: Stettler RF, Bradshaw HD, Heilman PE, Hinckley TM (eds) Biology of Populus and its implications for management and conservation. Natl Research Council Canada, Ottawa, pp 7-32

Felsenstein J (2004) PHYLIP (Phylogeny Inference Package) version 3.6. Distributed by the author. Department of Genome Sciences, University of Washington, Seattle

Fischer MA, Adler W, Oswald K (2005) Exkursionsflora für Österreich, Liechtenstein und Südtirol. OÖ Landesmuseen, Linz

Hamzeh M, Dayanandan S (2004) Phylogeny of Populus (Salicaceae) based on nucleotide sequences of chloroplast TRNT-TRNF region and nuclear rDNA. Am J Bot 91:1398-1408

Heinze B (2007) A database of PCR primers for the chloroplast genomes of higher plants. Plant Methods 3:4

Heuertz M, Hausman JF, Hardy OJ, Vendramin GG, Frascaria-Lacoste $\mathrm{N}$, Vekemans X (2004) Nuclear microsatellites reveal contrasting patterns of genetic structure between western and southeastern European populations of the common ash (Fraxinus excelsior L.). Evolution 58:976-988
Heuertz M, Carnevale S, Fineschi S, Sebastiani F, Hausman JF, Paule L, Vendramin GG (2006) Chloroplast DNA phylogeography of European ashes, Fraxinus sp. (Oleaceae): roles of hybridization and life history traits. Mol Ecol 15:2131-2140

Hewitt GM (2001) Speciation, hybrid zones and phylogeography or seeing genes in space and time. Mol Ecol 10:537-549

Hewitt GM (2004) Genetic consequences of climatic oscillations in the Quaternary. Philos Trans R Soc B: Biol Sci 359:183195

Huntley B, Birks HJB (1983) An atlas of past and present pollen maps of Europe: 0-13000 years ago. Cambridge University Press, Cambridge

Ingvarsson PK (2008) Mulitlocus patterns of nucleotide polymorphism and the demographic history of Populus tremula. Genetics 180:329-340

Kotlik P, Berrebi P (2001) Phylogeography of the barbel (Barbus barbus) assessed by mitochondrial DNA variation. Mol Ecol 10:2177-2185

Lazowski W (1997) Auen in Österrreich-Vegetation, Landschaft und Naturschutz. Monographien, Band 81. Umweltbundesamt, Vienna

Le Corre V, Machon N, Petit RJ, Kremer A (1997) Colonization with long-distance seed dispersal and genetic structure of maternally inherited genes in forest trees: a simulation study. Genet Res (Cambridge) 69:117-125

Lexer C, Fay MF, Joseph JA, Nica M-S, Heinze B (2005) Barrier to gene flow between two ecologically divergent Populus species, $P$. alba (white poplar) and P. tremula (European aspen): the role of ecology and life history in gene introgression. Mol Ecol 14:1045-1057

Lexer C, Buerkle CA, Joseph JA, Heinze B, Fay MF (2007) Admixture in European Populus hybrid zones makes feasible the mapping of loci that contribute to reproductive isolation and trait differences. Heredity 98:74-84

Lexer C, Joseph J, van Loo M, Prenner G, Heinze B, Chase MW, Kirkup D (2009) The use of digital image-based morphometrics to study the phenotypic mosaic in taxa with porous genomes. Taxon 58:5-20

Maliouchenko O, Palmé AE, Buonamici A, Vendramin GG, Lascoux M (2007) Comparative phylogeography and population structure of European Betula species, with particular focus on B. pendula and B. pubescens. J Biogeogr 34:1601-1610

Nathan R (2006) Long-distance dispersal of plants. Science 313:786788

Niklfeld H (1972) Der Niederösterreichische Alpenostrand-ein Glazialrefugium montaner Pflanzensippen. Jahrb Ver Schutze Alppflanzen -Tiere 37:42-94

Niklfeld H (1974) Zur Historischen Deutung von Pflanzenarealen am Ostrand der Alpen. Wissenschaftliche Arbeiten Burgenland $54: 46-52$

Palme AE, Semerikov V, Lascoux M (2003) Absence of geographical structure of chloroplast DNA variation in sallow, Salix caprea L. Heredity 91:465-474

Palme AE, Su Q, Palsson S, Lascoux M (2004) Extensive sharing of chloroplast haplotypes among European birches indicates hybridization among Betula pendula. B. pubescens and B. nana. Mol Ecol 13:167-178

Petit RJ, El Mousadik A, Pons O (1998) Identifying populations for conservation on the basis of genetic markers. Conserv Biol $12: 844-855$

Petit RJ, Aguinagalde I, De Beaulieu JL, Bittkau C, Brewer S, Cheddadi R, Ennos R, Fineschi S, Grivet D, Lascoux M, Mohanty A, Muller-Starck GM, Demesure-Musch B, Palme A, Martin JP, Rendell S, Vendramin GG (2003) Glacial refugia: hotspots but not melting pots of genetic diversity. Science 300:1563-1565 
Pons O, Petit RJ (1995) Estimation, variance and optimal sampling of gene diversity I. Haploid locus. Theor Appl Genet 90:462470

Pons O, Petit RJ (1996) Measuring and testing genetic differentiation with ordered versus unordered alleles. Genetics 144: $1237-1245$

Posada D, Crandall KA (2001) Intraspecific gene genealogies: trees grafting into networks. Trends Ecol Evol 16:37-45

Rajora OP, Dancik BP (1992) Chloroplast DNA inheritance in Populus. Theor Appl Genet 84:280-285

Reynolds JB, Weir BS, Cockerham CC (1983) Estimation of the coancestry coefficient: basis for a short-term genetic distance. Genetics 105:767-779

Rieseberg LH, Soltis DE (1991) Phylogenetic consequences of cytoplasmic gene flow in plants. Evol Trends Plants 5:65-84

Schneider S, Roessli D, Excoffier L (2000) Arlequin ver. 2.000: a software for population genetic data analysis. Genetics and Biometry Laboratory. University of Geneva, Switzerland

Slavov G, DiFazio SP, Strauss SH (2004) Gene flow in forest trees: gene migration patterns and landscape modelling of transgene dispersion in hybrid poplar. In: Den Nijs HCM, Bartsch D, Sweet $\mathrm{J}$ (eds) Introgression from genetically modified plants into wild relatives. CABI Publishing, Wallingford

Starmühlner F, Aschenbrenner L (1972) Naturnahe Landschaften, Pflanzen- und Tierwelt. In: Aschenbrenner L, Starmühlner F,
Ehrendorfer F (eds) Naturgeschichte Wiens in 4 Bänden. Jugend und Volk Verl.-Ges, Vienna

Stearns SC, Hoekstra RF (2005) Evolution. Oxford University Press Inc, New York

Stewart JR, Lister AM (2001) Cryptic northern refugia and the origins of the modern biota. Trends Ecol Evol 16:608-613

Taberlet P, Fumagalli L, Wust-Saucy AG, Cosson JF (1998) Comparative phylogeography and postglacial colonization routes in Europe. Mol Ecol 7:453-464

Tuskan GA, DiFazio S, Jansson S et al (2006) The genome of black cottonwood, Populus trichocarpa (Torr. \& Gray). Science 313:1596-1604

van Dillewijn C (1940) Zytologische Studien in der Gattung Populus L. Genetica 22:131-182

van Loo M, Joseph JA, Heinze B, Fay MF, Lexer C (2008) Clonality and spatial genetic structure in Populus $\mathrm{x}$ canescens and its sympatric backcross parent $P$. alba in a Central European hybrid zone. New Phytol 177:506-516

Widmer A, Lexer C (2001) Glacial refugia: sanctuaries for allelic richness, but not for gene diversity. Trends Ecol Evol 16:267-269

Willis KJ, van Andel TH (2004) Trees or no trees? The environments of central and eastern Europe during the Last Glaciation. Quaternary Sci Rev 23:2369-2387

Willis KJ, Rudner E, Sümegi P (2000) The full-glacial forests of Central and Southeastern Europe. Quaternary Res 53:203-213 